\title{
Understanding Knowledge through the Example of C. S. Peirce's Cosmology ${ }^{1}$
}

\author{
Enn Kasak \\ Raul Veede \\ School of Law \\ University of Tartu, \\ Näituse 20, \\ Tartu 50409, Estonia \\ E-mail:enn@kasak.ee \\ E-mail: raul.veede@gmail.com
}

\begin{abstract}
In the era of Charles Sanders Peirce, cosmology was similar to philosophy that was still aspiring to be scientific. Peirce, having worked as an astrophysicist, supported cosmology's strive towards science. In cosmology, one often relies on knowledge different from everyday knowledge: such knowledge is very general and is situated on the boundaries of what is known; it is very difficult to ascertain it empirically. After Karl Popper, a realist may distinguish between subjective and objective knowledge but this distinction does not suffice for cosmology. A pragmaticist following Peirce could distinguish knowledge about real ideas, which could be termed i-knowledge. This could mean being made party to or being grasped by real ideas functioning outside ourselves. Expressing all i-knowledge as propositional knowledge is difficult. However, non-propositional i-knowledge can sometimes be expressed as principles or paradoxically.
\end{abstract}

Keywords: cosmology, history of science, knowledge, i-knowledge, Charles Sanders Peirce, philosophy of science, pragmatism, pragmaticism, realism

\footnotetext{
1 We wish to express our gratitude to the journal Studia Philosophica Estonica for their permission to use materials published in the Estonian article 'Objektiivsest teadmisest C. S. Peirce'i kosmoloogia näitel ('On objective knowledge through the example of C. S. Peirce's cosmology', Studia Philosophica Estonica, 8.1, pp. 9-112).
} 
In the lifetime of Charles Sanders Peirce (1839-1914), cosmology was usually understood as a philosophical speculation on the nature of the universe. Scientific communities, however, tried to make this speculation consistent with (classical) physics of the time. ${ }^{2}$ In astrophysics, the necessity for a scientific cosmology became evident. For over ten years, Peirce worked as an astronomer, or, in the contemporary sense, as an astrophysicist. ${ }^{3}$ Thus it is probable that he encountered cosmological problems that, in the end, led to the development of scientific cosmology. ${ }^{4}$ In his contribution to cosmology, Peirce relied on his philosophically developed method that he himself considered scientific. He termed the method pragmaticism, emphasising its realism and trying to protect himself from other schools called pragmatism (CP 5.414). ${ }^{5}$

It seems that Peirce's metaphysical cosmology is easier to grasp when the use of the term 'knowledge' is clarified. In addition to empirically testable knowledge, arguments on cosmology often draw on knowledge of quite particular nature that is very general and is situated on the boundaries of what is known; it is very difficult to ascertain experientially and even thinking clearly about such knowledge may be difficult because human thinking might not be well suited for dealing with cosmological categories.

The article is structured as follows: In the first section, we will try to define knowledge in a social context, using Dworkin's (1986) treatment of community personified. With the help of knowledge thus defined, it is possible to consider scientific knowledge and knowledge that could be helpful in some discussions of scientific cosmology.

In the second section, we will show, pondering in Peirce's pragmaticist spirit, that when trying to understand Peirce's cosmological categories, it might make sense to substitute several terms denoting different types of knowledge for the single term of knowledge. This is useful in order to avoid the equivocal use of the term.

Cf Johann H. Mädler's (1873, ii, p. 223) discussion of Olbers' paradox.

3 See Feibleman, 1970, p. 20. For example, Peirce contributed much to the fact that the metre was defined on the basis of the wavelength of light, a definition that was current until 1983. Peirce's contribution to metrology indicates his wide range of interests.

4 Indirectly, this is evident from Peirce's assertion that he started studying philosophy due to his interest in cosmology (Peirce, 1994, 4.2; abbreviated below as CP 4.2; Peirce, 2013 will be below referred to as PCP).

5 Peirce considered other pragmatists too nominalist (Anderson, 1995, p. 19; Feibleman, 1970, pp. $25-$ $26,475)$. Peirce's realism will be discussed below. It is important to note that pragmatism is better known in its later guise (it has been claimed that William James and John Dewey misunderstood Peirce, see Feibleman, 1970, p. 29) and therefore one must emphasise that Peirce's position does not represent typical pragmatism. Despite the fact that pragmaticism is usually considered a form of pragmatism, the two differ greatly in the issue of the truth and therefore the two are considered as distinct below. In cases where the distinction is not material, we will use the term pragmat(ic)ism. 
In the third section, we will briefly discuss the categories of pragmaticist cosmology using the types of knowledge introduced in previous sections. We will also try to study how these categories could be interpreted by a contemporary cosmologist.

\section{Communal and individual knowledge}

According to the standard model of knowledge, which seems to have originated in Plato (Theaetetus, 210a), knowledge is justified true belief (JTB), whereas knowledge is borne by a subject and the object of knowledge is proposition (Pritchard, 2009, p. 6). This definition came into question when Gettier (1963) proposed examples of beliefs that are true and justified but are counterintuitive as knowledge. After Gettier's critique, ever more complex definitions of knowledge have been spawned and these are being complemented (cf. Sturgeon, 1995; Pritchard, 2009). We will not discuss this cascade of complements below, instead, we will try to find a way to make Gettier's case less compelling for scientific knowledge.

If a subject is an expert user of language like a scientist and even if we accept his views on truth and justification, this still is not knowledge in the sense of expert use of language. One cannot consider scientific knowledge as the knowledge of an individual, one must also consider the community. The community has a role in shaping individual knowledge. It is possible to form individual knowledge because we rely on collectively gained knowledge; to a degree, we participate in forming collective knowledge. Gaining knowledge in the sense of expert use of language might be well beyond individual capacity; in this case, the communal work of a field of science will be drawn on. For instance, existential problems concern everyone and these are solved collectively with the participation of ethics, the arts and religion.

After Dworkin (1986, pp. 167-168ff), we may consider a group of people competent in a field who communicate with one another (e.g., the body of scientists) as a community personified. ${ }^{6}$ Below, a personified community of scientists considered as a whole will be observed as a superperson; let this be $Z$. Also, it should be noted that the object of knowledge, what is known, cannot

$6 \quad$ It is debatable as to what extent it is possible to attribute to a community personified the properties or states of consciousness of an individual but Dworkin has convincingly shown that this train of thought has yielded interesting results at least in the philosophy of law. 
always be expressed in a proposition. ${ }^{7}$ More generally, we may speak about the object of knowledge ( $o$ ) that may be a proposition. But this object may be expressed otherwise, for instance as a paradox.

Now we can define the knowledge of a community personified after the scheme preceding Gettier:

$Z$ knows that $o$ if and only if (i) $Z$ believes that $o$; (ii) the belief of $Z$ that $o$ is true; and (iii) the belief of $Z$ that $o$ is justified while $Z$ is a knowing supersubject (a community personified) and $o$ is an object of knowledge that may be a proposition.

This could be termed $z$-knowledge, the justified true belief of the supersubject $Z{ }^{8}$ Experience demonstrates that communities of researchers in a field characteristically hold both specialist and general notions that do not usually require additional justification to the social group and are generally shared in the community. The body of scientists can be viewed as personified communities both as a whole and in parts; scientific knowledge can be seen as the knowledge of a respective community.

For example, an overwhelming majority of physicists hold the belief that the world described by physics is causal. Within the community, they are not obliged to justify this belief. On the other hand, the burden of proof is placed on those who express their doubts about this belief.' This might be interpreted as meaning that physicists as a community hold this belief. The belief in the causality of the physical world is true according to the majority the community (and may in fact be true) despite the possibility that different members of the community may be guided by different theories of truth. The same belief is held as justified by an overwhelming majority of the community despite the possibility that different members of the community may be guided by different

\footnotetext{
E.g., the knowledge of a paradox may be expressed as contradictory propositions. Trying to express knowledge of the incommunicable will result in an inadequate expression, however, it is possible for a member of the community to adequately understand it. A mathematician may understand another when an expression used is internally contradictory or void of meaning, like the expression set of all sets (Moore, 1990, pp. 191-192).

8 The constraints of space will not allow us to thoroughly discuss arguments justifying the use of expressions $Z$ knows and $Z$ believes analogically to the expressions $S$ (subject) believes and $S$ knows. We will leave the burden of proof to Dworkin and merely make a few remarks. Naturally, $Z$ knows does not mean that all subjects belonging to $Z$ agree. After Dworkin, their disagreements may be treated analogously to doubts occurring in the beliefs and knowledge of an individual. $S$ may doubt his knowledge sometimes or to a degree and seek additional justifications for his position. Peirce also seems to refer to the community of researchers when discussing how researches working in parallel achieve a truth (see Anderson, 1995, p. 19).

9 According to Peirce, if I believe something, I cannot start doubting it without a ground for doing so (CP 5.416).
} 
means of justification. However, the theories of truth and ways of justification in use may not vary to such an extent that would cause the user of any of these to be taken considerably less seriously in the community. In physics, for example, experimental justification is accepted and justification based on revelation is not accepted.

We might rather attempt to apply the standard definition of knowledge on a single subject. If a subject has immediate access to the content of the object of knowledge, such as the perceptions of a personal sense or cognitive constructions, this kind of knowledge could be termed s-knowledge and this seems to be in quite a good concordance with JTB.

Z-knowledge would allow itself to be modified in post-Gettier ways, but a need for the modification might not be necessary because naturalist methods seem to weaken counterarguments of the Gettier type. Moreover, such arguments may be used as additional requirements scientific justification has to account for. Furthermore, counterarguments that can be disputed by doubting the adequacy of individual intuition when it tries to assess whether something is knowledge also lose their edge. ${ }^{10}$ When scientific knowledge is mentioned below, it is z-knowledge where it has been presupposed that $Z$ has been contextually defined and verbal communication and cooperation within the personified community helps define beliefs and justifications better than in the case of a single individual. Unfortunately, collective error is possible even if research has been thorough. Thus, it would be more precise to say that a definition of scientific knowledge that relies on z-knowledge corresponds better to the collective nature of science than classical JTB but the problem of the inadequacy of the definition persists.

Both s-knowledge and $\mathrm{z}-\mathrm{knowledge}$ are founded on context that may be directly inexpressible in part or as a whole. This issue was already discussed by Kant who distinguished the category or intellectual concept [Notio, Verstandesbegriff] from the idea or concept of reason [die Idee, oder der Vernunftbegriff]. ${ }^{11}$ Ideas do not

10 Gettier's arguments are based on epistemologists' intuitive notions of knowledge. Experimental philosophical studies show that intuition on knowledge may be different in different groups. The experimental philosophical consideration gives enough ground to handle with caution a philosophical method that relies on the intuitions of a single, non-representative group such as epistemologists (Mölder, 2015).

11 See Kant, Kritik der reinen Vernunft, B 377/A $320(1968,326)$. Kant defines the idea in a way that ["Ein Begriff aus Notionen, der die Möglichkeit der Erfahrung übersteigt, ist die Idee oder der Vernunftbegriff $f^{*}$, according to Feibleman, Peirce interprets this justifiably as wholly subjective (Feibleman, 1976, p. 40). As Kant's ideas are derived from the nature of reason, they can be discussed as subjective but they entail something else also. Kant's ideas connect us with something we cannot know, however they let it be represented in our thinking, even invading thinking itself, being part of reason. 
bring direct benefits to applied experience of reason but play a (regulative) role by creating a background that consults and provides an order of things. Kant's intellectual concepts exist a priori but have meanings only in conjunction with objects of experience, they are not applicable outside experience. Both ideas and categories have to be treated primarily as subjective. Their source lies outside the object but is not perceptible. Kant denies the existence of universals as things but recognises universals as concepts that represent things. However, Kant is not a pure conceptualist for conceptions themselves are not universal-merely their use is universal (Oberst, 2015). Kant's universals belonged in logic and not in metaphysics. Kant thinks that human knowledge has two stems (logic and experience) that grow from a single root unknown to us. ${ }^{12}$

Kant's ideas and categories tend to be subjective and, in the issue of universals he is close to conceptualists. Peirce, on the other hand, is a realist and his realism, as opposed to scholastic realism, describes three different kinds of reals:

1) Those whose being lies in the substance of the thought itself, mere ideas, object logically possible, the object of pure mathematical thought for example;

2) Those whose being consists in their connexions with other things, existents, reacting things;

3) Those whose being consists in their connecting two or more other thingslaws, generals, signs, etc. In short, the real is the ultimately undeniable. (Anderson, 1995, p. 58)

That is real which has such and such characters, whether anybody thinks it to have those characters or not (CP 5.430). When talking about ideas, Peirce usually means conceptions (Peirce, 1878), but there may be something real behind them: "the idea does not belong to the soul; it is the soul that belongs to the idea." (CP 1.216). Ideas are not mere creations of this or that mind, but on the contrary have a power to "catch on" to those who think them (CP 1.217). Of course, thinking may involve inadequate or fictional conceptions that do not apply to reality, even though they are real in the sense that they are being thought about. Peirce calls these ideas false and the idea that Peirce finds true concerns something general and this is the real. Natural sciences also find it interesting. ${ }^{13}$ Below we prefer to refer to these with a more precise term 'real ideas'. A real idea is capable of influencing its holder in a way that in the latter's thought process

12 See Kritik der reinen Vernunft, B 30/A 16 in Kant, 1968, p. 66.

13 Ideas may be false in the sense that they need improvement or clarification, which can be done through an experience of surprise (further on this see Cooke, 2015). 
it is represented as a conception (or idea in the sense that Peirce generally uses it). A realist believes that part of real ideas are universals, represented by general concepts in thinking. According to Peirce, reality is cognisable, and it is possible for us to acquire knowledge about real ideas and this could be an interesting subject for researchers.

\section{On the types of knowledge}

It is possible to distinguish between the types of knowledge according to their degree of generality. Thus we have knowledge of facts, knowledge of universals (including laws of nature) and yet more general knowledge (of Kant's ideas) that systematises knowledge of categories and universals and that we can try to formulate as principles. A realist will strive to see something that really exists behind ideas and a large share of scientists (or maybe even a majority of them) tend to be realists. A realist may acknowledge knowledge about real ideas, which could be termed i-knowledge. To a realist, Kant's ideas or concepts of reason should stem from something real and not be rooted in the nature of thinking itself. I-knowledge of this could mean being made party to or being grasped by real ideas functioning outside ourselves. Expressing this as propositional knowledge is quite problematic or impossible, sometimes it can be expressed as principles or by means of paradoxes. Expressing this non-propositional $\mathrm{i}$-knowledge as principles is also problematic.

I-knowledge is perhaps more commonly encountered in physics and cosmology than in other fields; also, metaphysics takes interest in this. According to Peirce, "belief proper has nothing to do with science" (CP 1.239Fn). A scientist may be characterised by his inclination to doubt and test his knowledge and beliefs. In the case of i-knowledge, the scientist is in an awkward situation because it is impossible (or seemingly almost impossibly difficult) to test ideas by means of experimenting. For example, if the cosmological idea is formulated as a principle, it is very difficult to test the validity of a principle in the whole universe for the attainable universe forms a minuscule and perhaps even an atypical part of the whole. On the basis of i-knowledge it is possible to construct arguments of metaphysical kind, and while they can be discussed in combination with arguments of the natural sciences, the arguments cannot be tested with conventional methodologies, such as the cosmological principles of Giordano Bruno. Some of these arguments can be falsified, for example, the validity of the 
isotropy of the universe can be questioned if the so-called dark flow is eventually confirmed. ${ }^{14}$ Below it is suggested that Peirce has rather successfully applied i-knowledge in his cosmological works (relying on his devised philosophical method).

If we assume the realist position in the style of Peirce (see, e.g., Peirce, 1878) and acknowledge the realism of some object of knowledge, it appears that the term 'knowledge' is sometimes used equivocally or ambiguously and not only in the common language use but also in expert use of language. This is not about obvious equivocality—about how knowledge may be understood as knowing-that or, for example, familiarity with or understanding of how something is done. This is specifically about the equivocal use of knowing-that. The main problem is that a realist does not necessarily have to embrace the subject in the knowledge. For example, Karl Popper coined the term 'World 3' which embraces the objective content of thought (Popper, 1968, pp. 333-334). Popper distinguishes subjective knowledge from objective knowledge as part of World 3. This includes problems, critical discussions, theories, etc. but these exist without the subject. The elements of objective knowledge are the products of people and are not perfect. According to Popper, these resemble Frege's notions of the objective content of thought and differ from the ideas in the sense of Plato (Popper, 1994, pp. 108-109), however, these are not the ideas in the sense of Kant because this knowledge is objective, whereas Popper postulates the existence of World 3 as independent of the other worlds. The concept of i-knowledge, coined in order to understand the ideas in the sense of Peirce, differs from Popper's treatment in the respect that the ideas of Peirce are not products of humans but are not the ideas of Plato because ideas in the sense of Peirce need not be perfect or immutable (CP 6.13). In addition to the Kantian ideas, Peirce includes among i-knowledge also the knowledge about the universals, including laws of nature; this subset of i-knowledge can be hold to be propositional knowledge.

Both s- and z-knowledge introduce the issue of the truthfulness of the object of knowledge. On the basis of the correspondence theory of truth, a realist may say that the discussion of objects embraced by a proposition is successful in the case of a true proposition and unsuccessful in the case of a false proposition. A pragmat(ic)ist will pay attention to whether the proposition could be pragmatically operable, that is, if the proposition is true, then something in empirical experience or mental worlds is different when compared with the

14 Dark flow describes the observable phenomenon of a possible additional component of the velocity of all galaxy clusters, indicating their systematic flowing in a common direction (Kashlinsky et al., 2008). 
state of affairs if the proposition is false (James, 1907, p. 142). Proposition and its truth value ought to be at least potentially operable, either for a person, personalised community or, in fact, any subject capable of understanding the contents of the proposition.

Popper approached knowledge without subject, and his World 3 allows discussing theoretical knowledge as if it was fact-based knowledge. Mathematicians have tried to approach knowledge in a way that it can be held by any system capable of handling the relation of notation-denotation. This has proven useful in creating artificial intelligence. Peeter Lorents defined the element of knowledge as a consecutive pair $<$ sign, significance $>^{15}$ and this does not contain the subject in a manifest form (Lorents, 2001), but like data that has to be on a carrier, the signsignificance relation must also have a carrier, which could be called a knower. The knower possesses the language that determines the syntax of signs and the semantics of significance. Significance, in turn, may be a sign of something else, and so on.

Following Peirce's example, we may say that sign is a sign only if there is an object that the sign stands for - there must be object, sign and interpretant (CP 2.228). The object may belong to a certain world, be it physical, mental or fictional. By trying to improve Lorents's atom of knowledge, a realist following Peirce can define realist knowledge (henceforth $r$-knowledge) that could be the consecutive triplet <object, sign, interpretant (significance) $>$ in which an object in the real world would correspond to the token. Owing to the limitations of scope of the article, this relation will not be described mathematically following Lorents's example, but it is important to note that the carrier of the relation (knower) could only potentially exist. Objective realist knowledge requires the (potential) existence of an interpretant of infinite power, whereas the knowledge of the interpretant of finite power may be more or less incomplete. In a natural language, it would sound as follows: r-knowledge is knowing how things are in the real world.

The propositional part of $\mathrm{i}$-knowledge belongs to $\mathrm{r}$-knowledge. Realist science aspires towards $\mathrm{Z}$ being as powerful carrier of the relation of object-signsignificance as possible. If we assume the (potential or actual) existence of a carrier with an infinite power of the knowledge relations, then perhaps there is not much difference in terms of objective knowledge whether it is the world of objective knowledge (Popper's World 3), or the scholastic view that real objective knowledge exists in the mind of God, or even something other than that.

15 A follower of Peirce could opt for the terms 'interpretant' or 'meaning' instead of 'significance'. 
As far as knowledge is concerned, it is impossible to avoid the issue of justification. The theories of justifying beliefs could be divided into internalist theories - the subject must have access to the basis of his beliefs, and externalist theories - the subject may not have access to the basis of knowledge or justified belief. If the subject does not have immediate access to the content of the proposition, the views of internalists diverge: to justify beliefs, he may choose either a foundational or coherentist stance (Sturgeon, 1995). A realist does not find it difficult to conform to foundationalism if he tries to relate the justification of basic beliefs to reality, but a position has to be chosen on how reality determines the justification. A realist may attempt to demonstrate how different internalist theories conform to reality but it is not easy, because there is no single generally accepted mechanism that could ensure the adequacy of a justified belief in the realist sense. An internalist realist may postulate that the subject has an unusual cognitive faculty-a sense of truth-that tells the subject whether a proposition is true or not; as other faculties, the sense of truth may deceive but, like an experienced observer, an experienced 'truth-observer' will err more seldom. Nevertheless, as far as such unusual postulates are concerned, a realist must find additional arguments to support the posing of such postulates. Peirce appears to be precarious in the issue of the probability of direct observance. In some works he seems to argue that there is no direct access to reality (1868), whereas in others he acknowledges the power of direct intuition (1908). He calls such method of direct perception of truth 'musement' (Peirce, 1908, pp. 93ff) and apparently it can be interpreted also in terms other than purely theological ones. Perhaps the issue of direct truth-observance emerges more in relation with objects of i-knowledge, whereas theology has studied some of these objects more often than science and Peirce himself categorises it among phenomena remaining outside the realm of science.

An externalist, or more precisely, a reliabilist, will link the justification process of the justification with reliability and to do that he follows a procedure which results in true rather than false beliefs. For a reliabilist, justification is not strictly necessary for knowledge but the beliefs have to be achieved in a reliable manner. Unfortunately, it is not clear how to test reliability externally. In science and the social context the internal stance is preferred-if it is considered reliable by $Z$, then it is reliable. At the same time, attempts are made to relate knowledge with external justification, for example, experiments that may yield unexpected results and transform the procedures that are considered reliable and the content of reliable beliefs. Science mainly deals with knowledge that 
can be communicated verbally, and reliability has been defined quite clearly in the case of the given Z. For example, in physics, reliable knowledge can be tested experimentally. Let us call empirically testable knowledge e-knowledge. This is experiential knowledge that can be justified by different means.

Realism is threatened by an infinite regression toward super-realism where behind every reality there is a more real reality. ${ }^{16}$ Here, pragmat(ic)ism draws a line from which movement along the hierarchy of realities is inevitably speculative, because a reality that is not pragmatically operable cannot be the object of a sensible discussion. Peirce's realist idea is pragmatically operable because it is capable of influencing the subject. However, the source of realist ideas can be an object of intelligent discussion only when its pragmatic operability can be seen, either as an object of direct perception or in a role regulating perception or thinking. If a true proposition that is the object of belief describes real relationships between real objects, it is possible to speak about its veracity even when no subject or social group is conscious of it. A pragmat(ic)ist may say that due to operability it is potentially possible to become conscious of it. John Poinsot presented similar arguments in his discussion of the sign and the sign relationship already in 1632, when he said that for signifying in a reality it suffices to be sign potentially (1985).

It seems that a pragmaticist perspective could use different types of knowledge, listed and briefly described below:

- s-knowledge: the subject has direct access to the content of the object of knowledge, e.g., personal perception or thought construction;

- $z$-knowledge: the subject of knowledge is personalized community;

- e-knowledge: knowledge that can be empirically tested;

- $\quad r$-knowledge: realist knowledge in the pragmaticist sense, a consecutive triplet $<$ object, sign, significance $>$, in which an object in the real world corresponds to a sign;

- i-knowledge: knowledge about real ideas. In case such a knowledge could

16 A realist may find that the material universe one believes to be inhabiting is real, something similar to what, for example, researchers of natural sciences would find real. But it is also possible that this so-called observable universe is not primary and is generated by some primary reality which may be very different from the observable universe. In this case, a realist may find primary reality more real and the observable universe less real. For example, a primary universe could be, in fact, a computer programme generating the observable universe with all the living things inside it in the form of a computer simulation (see, e.g., Bostrom, 2003). Then again, even this universe in which the said computer programme is run may be generated by an even more primary reality. The view according to which there is another, even more "real" reality behind any reality, is called super-realism. 
be clearly seen as propositional knowledge, it can be described as a special case of $r$-knowledge. Otherwise, this could mean being made party to or being grasped by real ideas functioning outside ourselves. Expressing this as propositional knowledge is quite problematic, or even impossible. The object of knowledge is revealed through the regularity of other knowledge or by means of unusual cognitive abilities (e.g., truth-observance). The line between propositional and non-propositional i-knowledge is vague and changing.

The above types do not form a taxonomic classification of the term knowledge because the semantic fields of the specified terms overlap and it is not obvious if they cover the whole semantic field of the term knowledge or extend beyond it. Cosmology, it seems, also has a need for $\mathrm{r}$ - and i-knowledge.

\section{On some aspects of Peirce's cosmology}

In Peirce's time, the dominating view was that the universe is infinite, eternal, homogeneous, isotropic, materially uniform and stationary. ${ }^{17}$ Even though Peirce himself regarded his cosmology as scientific, it is not a good idea to identify it with scientific or the physicists' cosmology in the modern sense of the word. For Peirce, cosmology was "mathematical metaphysics" (CP 6.213), which should be logic. In the course of perception, our logic should shift closer to the logic of the universe, which Peirce believes is that towards which one can aspire rather than attain (CP 6.189). "The Truth, which is the universe of all [possible?] ${ }^{18}$ universes, and is assumed on all hands to be real," (CP 5.506), whereas cosmology is narrower in the sense that it is involved with only really existing [actual?] universe. ${ }^{19}$

Following his triadic logic (firstness, secondness, thirdness), Peirce coined three cosmological categories (CP 6.490):

- Tychism ${ }^{20}$ - chance, in the sense of 'total possibility'; chance is a real force that makes something happen; in combination with agapism, this may be taken to mean as luck or a happy chance;

\footnotetext{
All these principles are backed by solid history that cannot be discussed here in further detail. Addition by the authors of this article.

See Feibleman, 1970, p. 400. This might be a hint to a possible worlds semantics.

20 In Greece, Tyche was the deity of fortune and prosperity, and $\tau \dot{\chi} \chi \eta$ could stand for 'probability', 'incident' or 'chance', as in lucky chance.
} 
- Agapism ${ }^{21}$ —evolutional love in the sense of 'directed evolution'; this may be taken to mean a universal development and ordering active principle that teleologically directs towards the ultimate cause; in the context of theology, this can be understood as the Creator's love toward the created;

- Synechism ${ }^{22}$ - uninterrupted continuity, perhaps also in the sense of 'harmonious consistency'; synechism attempts to treat everything as continuous.

According to Peirce, the Universe has an initial state (CP 6.490; CP 8.317; CP 1.411), primeval chaos, pure nothing (CP 5.431). But this nothing is the creator of the laws of nature, not the other way round. Nothing has yet happened, but still it is the totality of all possible possibilities and determinations, all potentialities (CP 6.33; CP 6.265; CP 1.447). Chances happen inevitably, tychist chance is an operating force that gives the possibility of changing and growing and may contravene the conservation of energy; it is inexplicable but it helps explain the laws of nature (CP 6.613). Chance causes fluctuations (CP 6.47) and causes changes in the universe or evolutional cosmology.

Agapist directedness leads the active development of the universe, chance alone does not suffice (CP 5.172), agapism reflects teleological growth and love (CP 6.287), the development of which up to its end state is the ultimate cause of the universe (CP 6.33). Synechism helps to understand that everything is continuous. This represents uninterrupted flow, regularity and consistency (CP 1.172). The beginning of the universe was in infinite past and its evolution goes on until the universe has become an absolutely perfect, rational and symmetric system (CP 6.33). All Peirce's categories merit further discussion, but it is possible to say something on the basis of the general framework presented above.

As i-knowledge, Peirce presents the knowledge that there is nothingness at the beginning of the universe but that nothingness is a creative power, and the universe evolves teleologically by guiding love towards the end reason. Following this line of thought it may first seem that in order to understand Peirce's cosmology one must definitely adopt a theological approach, and it has been done (Robinson, 2010). Although Peirce himself seems to do the same, it can definitely be avoided and an atheological approach is equally possible. For example, Feibleman (1970, pp. 416-418) tries to emphasise that Peirce regards

21 The primary meaning of the Greek word áyó $\pi \eta$ is 'love'. Peirce applies it in the sense of evolutionary love that starts and directs teleological development.

22 The Greek word $\sigma v v \varepsilon \chi \eta ́ s$ means 'continuous', 'uninterrupted'. With the added -ism suffix, it stands for continuity or uninterruptedness. 
theology as a means to approach issues related to spirit, ideas and morals rather than an end to the means. Science philosopher Nicholas Maxwell, who could hardly be accused of excessive affinity to religion, applies elements of theology in more or less the same manner.

When modern researchers attempt to approach phenomena that traditionally have been studied by theology, the thinking of atheist researchers is often clouded by a phenomenon that Thomas Nagel has called 'fear of religion'. He notes that atheists have no more reason to be alarmed by fundamental and irreducible mind-world relations than by fundamental and irreducible laws of physics (Nagel, 2003, pp. 130-131). ${ }^{23}$ Quite possibly, some views, methods and trails of thought used by theology could be applied in science. It seems that Peirce's theological contemplations were at least partly motivated by the fact that he did not find it necessary to distance himself from theology since he had no fear of religion. As a fallibilist, Peirce argues that knowledge cannot be perfect and he also seems to imply that reality might not be perfect as, for example, laws of nature are capable of developing and are thus arbitrary and imperfect (CP 6.91). Imperfect reality may also allude to that Peirce used rather than acknowledged theology.

In the case of i-knowledge, scientists as a personified community function, so to say, as a commune of observing the truth: if truth is not manifested through the regularity of knowledge, then one possible instrument for gaining i-knowledge is the human sense of truth, conventional concepts are agreed on by synchronising 'observations of truth' in the communication process of the community. As a scientific phenomenon, $\mathrm{i}$-knowledge is something similar to paradigmatic knowledge. The observed need not be ideally captured but may need further observations and reassessments and being conscious of the technique of observation, using the technique and perfecting it. How to do it in practice is limited with the principles, limitations of rules and methods accepted by the community of scientists in question.

To sum up some of the key aspects in Peirce's cosmology we will include here contemporary interpretations, some of which, as far as the article's authors are aware, have not been a subject of serious dialogue, even though they have been

23 With his fear of religion, Nagel does not refer to hostility toward religion or the questionability or inadequacy of religious beliefs. The mind of an atheist scientist or philosopher shuts down when he feels that a certain line of thought might need religious or theological approach. 
discussed. ${ }^{24}$ All the interpretations and comments merit further study in the future. Below, for the sake of clarity, Peirce's views are marked with letter P and comments or interpretations with C.

P: The beginning of the universe is chaos, pure nothing (CP 6.490; 8.317) but it has a Tychic power, creative force; there is absolute determination and the possibility of all determination, a set of all potentialities, it contains, initially in an indefinite state all potentialities (CP 6.33; 6.265; 1.447). There was no regularity and nothing existed or really happened (CP 1.411).

C: Here we can see a notion, at the time quite novel, of the universe with a moment of beginning; in the choice that is realised out of all possibilities, we may see a spontaneous symmetry breaking that is the fundamental idea behind the current unified field theory. ${ }^{25}$

P: Tychism presents a possibility as a reality, which contravenes the law of conservation of energy (CP 6.613).

C: Since Noether's theorem (1918) it has been known that the conservation of energy is connected to homogeneity of time. Since time could not be homogeneous with the first moment of the Universe, energy need not always be conserved over time. ${ }^{26}$

P: Even the laws of nature come into being and are the result of evolution (CP 6.91). It is false to assume that the state of things and the laws of nature singularly determine what comes next (CP 6.36-6.37).

C: Today, it is thought that the set of laws of nature might well be different. After the invention of quantum theories, we should agree with Peirce on the

24 E.g., the theoretical physicist Lee Smolin has recognised the main postulates, predictions and setups of problems of Peirce's cosmology (Smolin, 2013, pp. 125-129). Nobel Prize winner Steven Weinberg (2003, p. 205) refutes the suspicions as if philosophy has nothing new or useful to say to physicists about reality and gives Peirce's philosophy as a positive example. These questions are briefly touched upon also by Kalevi Kull (2014) and Andrew S. Reynolds (2014), who provide a somewhat more moderate assessment of Peirce's achievements.

25 Peirce's discussion of 'the universe of all universes' and the 'real universe' can be interpreted in many ways - for example, it could be an understanding of multiverse or, for example, applying possible worlds semantics, etc. This line of argument, too, merits further study.

26 In a model where the total energy is constant but worlds or domains of so-called adverse energies emerge, the energy of the attainable universe may not be invariant. 
lack of predetermination of states of things.

P: According to synechism, everything that exists is continuous (CP 1.172).

C: This view was accepted back then but is debatable now. An interesting detail occurs in Peirce's opinion that contemporary science did not allow for the belief that the universe is not infinite in space and time (CP 6.4196.421). He seems to avoid asserting anything here but as he speaks about infinite past and infinite future (CP 6.33), the postulate of the infinity of time may be seen here.

P: The universe develops teleologically, guided by evolutionary love, towards its ultimate cause (CP 1.590).

C: Today, it is thought that there are rules governing the Universe's evolution and arguments over the so-called anthropic principle do not allow for dismissing the possibility that the Universe might have an ultimate cause. Should this be love? This will remain unanswered for now and true scientists consider this a speculation. But, as the tale of the cosmological constant teaches us, notions originating in ordinary conditions may not work on the cosmological scale. The Universe may contain other phenomena that do not disclose themselves on a small scale (e.g., on the scale of one megaparsec) but are manifested on a cosmological scale. There can be negentropic processes on a cosmological scale, analogous to cosmological thrust, which cannot be tested in a small laboratory. It is possible that the phenomena that those who are partial to the so-called intelligent design theory or herald cosmic love try to apply for their benefit are manifestations of this type of phenomena.

\section{Conclusion}

Somewhat undeservedly, Charles Sanders Peirce's cosmology has been overshadowed by his achievements in semiotics and logic. Nevertheless, it should be taken seriously. In cosmology, one often relies on knowledge different from everyday knowledge; in order to discuss such knowledge, it is necessary to distinguish between different types of knowledge. A pragmaticist following Peirce would pay attention to knowledge of real ideas; this could be termed i-knowledge. This seems to be being made party to or being grasped by real ideas 
functioning outside ourselves. It is problematic to express this as propositional knowledge. The constraints of space will not allow us a more thorough discussion on Peirce's cosmology but it is possible to briefly envisage how a cosmologist today could interpret categories of pragmaticist cosmology. We may find much controversy or dubiousity in Peirce's cosmology but we should acknowledge how he anticipated much of the foundational ideas of scientific cosmology to come. Maybe we can learn from the mistakes and successes of Peirce when forecasting what ideas may be viable in future cosmology.

On the basis of i-knowledge as a form of objective knowledge, the scientist may consciously be involved in studying reality and into naturalist discussions arguments of a metaphysical kind that we are so far unable to verify. But it seems to be impossible to search for new methods and possible solutions without posing the problem of verifying such arguments.

\section{Acknowledgements}

The authors are grateful to Ott Heinapuu, Andres Luure and Peeter Lorents for their valuable comments, and editor Kait Tamm for her suggestions and for translating some passages.

\section{References}

Anderson, D. R. (1995), Strands of System: The Philosophy of Charles Peirce, West Layfayette, IN: Purdue University Press.

Bostrom, N. (2003), 'Are You Living in a Computer Simulation?' Philosophical Quarterly, vol. 53, no. 211, pp. 243-255. https://doi.org/10.1111/1467-9213.00309

Cooke, F. E. (2014), Peirce and the 'Flood of False Notions', in T. Thellefsen \& B. Sorensen (eds.) Charles Sanders Peirce in His Own Words, Boston \& Berlin: Walter de Gruyter, Inc., pp. 325-329. https://doi.org/10.1515/9781614516415.325

Dworkin, R. (1986), Law's Empire, Cambridge, MA: Harvard University Press.

Feibleman, J. (1970), An Introduction to the Philosophy of Charles S. Peirce, Cambridge, MA: The M.I.T. Press.

Gettier, E. L. (1963), 'Is Justified True Belief Knowledge?' Analysis, vol. 23, no. 6 (June), pp. 121-123. https://doi.org/10.1093/analys/23.6.121 
James, W. (1907), "Pragmatism's Conception of Truth," The Journal of Philosophy, Psychology and Scientific Methods, vol. 4, no. 6 (Mar 14), pp. 141-155. https://doi.org/10.2307/2012189

Kant, I. (1968), Werke in zwölf Bänden. III. Kritik der reinen Vernunft I, Frankfurt am Main: Suhrkamp.

Kull, K. (2014), Physical Laws are not Habits, while Rules of Life are, in T. Thellefsen \& B. Sorensen (eds.), Charles Sanders Peirce in His Own Words, Boston \& Berlin: Walter de Gruyter, Inc., pp. 87-94. https://doi.org/10.1515/9781614516415.87

Kashlinsky, A.; Atrio-Barandela, F.; Kocevski, D. \& Ebeling, H. (2008), 'A measurement of large-scale peculiar velocities of clusters of galaxies: results and cosmological implications,' Astrophysical Journal, vol. 686, pp. 49-52. https://doi.org/10.1086/592947

Lorents, P. (2001), 'Formalization of data and knowledge based on the fundamental notation-denotation relation,' International Conference on Artificial Intelligence (ICAI'2001) - Conference Proceedings, CSREA Press, vol. III, pp. 1297-1301.

Mädler, J. H. (1873), Geschichte der Himmelskunde von des ältesten bis auf neueste Zeit, Vol. II, Braunschweig: George Westermann.

Maxwell, N. (2010), Cutting God in Half-And Putting the Pieces Together Again: A New Approach to Philosophy, London: Pentire Press.

Mölder, B. (2015), 'Against intuitions in philosophy,' Problemos, vol. 87, pp. 205-213.

Moore, A. W. (1990), The Infinite (Problems of Philosophy), London \& New York: Routledge.

Nagel, T. (2003), The Last Word, Oxford: Oxford University Press. https://doi.org/10.1093/0195149831.001.0001

Noether, E. (1918), 'Invariante Variationsprobleme,' Nachr. D. König. Gesellsch. D. Wiss. Zu Göttingen, Math-phys. Klasse, pp. 235-257.

Oberst, M. (2015), 'Kant on Universals,' History of Philosophy Quarterly, vol. 32, no. 4, pp. 335-352.

Peirce, C. S. (1994), The Collected Papers of Charles Sanders Peirce. Editorial introduction by J. Deely, Membra Ficte Disjecta: Electronic edition (In text: CP).

- (2013), The Published Works of Charles Sanders Peirce, Third Digital Edition, Institute for Studies in Pragmaticism. Retrieved from http://www.pragmaticism. net/works/guide.html [accessed 23 Oct 2016] (In text: PCP).

— (1868, PCP 00026), 'Questions concerning certain Faculties claimed for Man,' The Journal of Speculative Philosophy, vol. 2, no. 2, pp. 103-114.

(1878, PCP 00119), 'How to Make Our Ideas Clear,' Popular Science Monthly, vol. 12 , pp. $286-302$.

- (1902, PCP 00987), “Paulsen's Kant,” The Nation, vol. 75 (11 Sep), pp. 209-211.

(1908, PCP 01126), 'A Neglected Argument for the Reality of God', The Hibbert Journal, vol. 7 (Oct), pp. 90-112. 
Plato (1997), Theaetetus, in M. Cooper \& D. S. Hutchinson (eds.) Plato Complete Works, Indianapolis: Hackett Publishing Company, pp. 157-235.

Poinsot, J. (1985), Tractatus de Signis: The Semiotic of John Poinsot (Interpretive Arrangement by J. N. Deely), Berkeley, Los Angeles \& London: University of California Press.

Popper, K. R. (1968), Epistemology Without a Knowing Subject, in B. Van Rootselaar \& J. F. Staal (eds.) Logic, Methodology and Philosophy of Science III, Amsterdam: NorthHolland Publishing Company, pp. 333-373. https://doi.org/10.1016/S0049-237X(08)71204-7

— (1994), Objective Knowledge: An Evolutionary Approach, Oxford: Clarendon Press.

Pritchard, D. (2009), Knowledge, London: Palgrave Macmillan. https://doi.org/10.1057/9780230242241

Reynolds, A. S. (2014), Science and Metaphysics, in T. Thellefsen \& B. Sorensen (eds.) Charles Sanders Peirce in His Own Words, Boston \& Berlin: Walter de Gruyter, Inc., pp. 451-456.

Robinson, A. (2010), God and the World of Signs, Leiden \& Boston: Brill. https://doi.org/10.1163/ej.9789004187993.i-382

Smolin, L. (2013), Time Reborn, New York: Houghton Mifflin Harcourt.

Sturgeon, S. (1995), 'Knowledge,' in A. C. Grayling (ed.) Philosophy 1: A Guide through the Subject, Oxford: Oxford University Press, pp. 10-26.

Weinberg, S. (2003), Facing Up: Science and Its Cultural Adversaries, Cambridge, MA \& London: Harvard University Press

Enn Kasak is visiting associated professor at the School of Law, University of Tartu, former astrophysicist researching history and philosophy of science.

Raul Veede is a graduate student at the University of Tartu, researching history and philosophy of science, particularly that of the Early Modern Age. 